\title{
Dilemmas Within the Korean Health Insurance System
}

\author{
Donghwi Park', Min Cheol Chang ${ }^{2}$ \\ ${ }^{1}$ Department of Physical Medicine and Rehabilitation, Ulsan University Hospital, University of Ulsan College of Medicine, Ulsan, Korea; ${ }^{2}$ Department \\ of Physical Medicine and Rehabilitation, Yeungnam University College of Medicine, Daegu, Korea
}

The health insurance system in Korea is well-established and provides benefits for the entire national population. In Korea, when patients are treated at a hospital, the hospital receives a partial payment for the treatment from the patient, and the remaining amount is provided by the health insurance service. The Health Insurance Review and Assessment Service (HIRA) assesses whether the treatment was appropriate. If HIRA deems the treatment appropriate, the doctor can receive payment from the health insurance service. However, this system has several drawbacks. In this study, we aimed to provide examples of the problems that can occur in relation to HIRA assessments in Korea through actual clinical cases.

Key words: Health insurance system, Health Insurance Review and Assessment Service, Payment, Patient, Korea

Korea first introduced its health insurance system in 1977, and within 12 years (by 1989), the system had been expanded to cover the entire national population. This is considered a remarkable success, with no precedent worldwide. In Korea, when patients are treated at a hospital, the hospital receives part of the treatment cost from the patient and the rest is then paid by the National Health Insurance Service (NHIS). For example, a hospital receives around 10000 Korean won (KRW; US\$10) for treating a patient with a common cold. Of this, approximately $3000 \mathrm{KRW}$ is paid by the patient for the consultation, and the remaining $7000 \mathrm{KRW}$ is requested to be paid by the NHIS, which is subsidized by the health insurance fees paid by the national population. The Health Insurance Review and Assessment Service (HIRA) acts as an intermediary by as-

Received: March 11, 2020 Accepted: May 12, 2020

Corresponding author: Min Cheol Chang, MD

Department of Physical Medicine and Rehabilitation, Yeungnam

University College of Medicine, 170 Hyeonchung-ro, Nam-gu,

Daegu 42415, Korea

E-mail: wheel633@gmail.com

This is an Open Access article distributed under the terms of the Creative Commons Attribution Non-Commercial License (https://creativecommons.org/licenses/bync/4.0// which permits unrestricted non-commercial use, distribution, and reproduction in any medium, provided the original work is properly cited. sessing whether the request is appropriate. If the treatment is deemed inappropriate, the doctor will not receive payment for the treatment costs. However, this health insurance system has drawbacks. We therefore aimed to provide examples of the problems that can occur in relation to HIRA assessments in Korea through actual clinical cases.

\section{Case 1}

A 28-year-old man visited the physical medicine and rehabilitation department of our hospital presenting with weakness in both hands and wrists, which had started 2 years prior and had progressed slowly. He had weakness in the fingers and wrist extensors of both upper limbs (Medical Research Council score 2/5). He showed no sensory deficits. On an electrophysiological examination, the compound motor action potential showed decreased amplitude in the radial nerves of both sides, with conduction block. The sensory nerve action potential in both upper limbs showed no abnormal findings. Cervical magnetic resonance imaging showed no abnormalities. Multifocal motor neuropathy (MMN) was diagnosed using the established diagnostic criteria [1]. According to the health insurance reimbursement criteria, intravenous immunoglobulin (IVlg) can be used to treat MMN. We administered IVlg at a 
dose of $2 \mathrm{~g} / \mathrm{kg}$ over 5 days, and the patient's motor weakness had recovered almost completely at a 2-week follow-up. Subsequently, we planned to conduct IVIg administration with a monthly infusion of $1 \mathrm{~g} / \mathrm{kg}$. At the 2-month follow-up, his recovered motor function was maintained.

However, HIRA did not approve IVIg treatment for this patient. The reason was that the diagnosis of MMN was unclear. Ultimately, the costs of this treatment had to be borne by the hospital, and treatment of the patient with IVlg had to be discontinued because it had become an illegal act. The diagnosis was made based on previously established criteria. The fact that the patient responded well to IVIg treatment was a finding that further increased our confidence in the diagnosis. We asked what aspect of the diagnosis was unclear, but there was no response to this question, and we were asked instead, "Has the patient seen a neurologist?"We requested a re-assessment, but the result was the same, and we could no longer use IVIg. Two months later, the patient's motor function had reverted to its state before treatment, and the patient is currently unable to receive treatment and unable to use his hands. This is a situation in which treatment is needed but cannot be provided.

\section{Case 2}

A 44-year-old man was diagnosed with ankylosing spondylitis at a department of rehabilitation medicine 5 years prior, and had been using non-steroidal anti-inflammatory drugs and sulfasalazine. Recently, despite this medication, the patient had experienced worsening of pain and morning stiffness in his neck, middle and lower back, and both buttocks. There was no improvement in symptoms even after changing the type of non-steroidal anti-inflammatory drug; therefore, after checking the reimbursement criteria for tumor necrosis factor (TNF)- $\alpha$ inhibitors to ensure that they could be used by the patient, a subcutaneous TNF- $\alpha$ inhibitor injection (golimumab, $50 \mathrm{mg}$ ) was administered once per month. The patient's symptoms improved and the pain and morning stiffness became bearable. When assessed using the Bath Ankylosing Spondylitis Disease Activity Index, the patient showed a score of 6.2 points before TNF- $\alpha$ inhibitor use and 1.2 points after [2]. However, HIRA did not approve TNF- $\alpha$ inhibitor treatment for this patient. The reason was because the sacroiliitis grading (New York criteria) on the radiograph was interpreted as bilateral grade 1-2 sacroiliitis by a radiologist [3]. According to the reimbursement criteria, TNF- $\alpha$ inhibitors can be used for sacroiliitis of grade 2 and above. However, because the radio- graphs clearly showed bilateral sclerosis of the sacroiliac joint, we had graded the sacroiliitis as grade $2-3$. We requested a reassessment, but the result did not change. We had no choice but to discontinue TNF- $\alpha$ inhibitor treatment and to restart treatment with the patient's previous medications. The patient's pain and restricted range of joint motion worsened to unbearable levels again. We obtained further X-ray images, this time without grading, and they were interpreted by a radiologist as showing poor margins with irregularity of both sacroiliac joints. In our opinion, these scans appeared to be grade 2 or 3 and we requested another assessment from HIRA, but the use of TNF- $\alpha$ inhibitors was not approved, as the approval decision was based only on the results of the previous radiographs. The patient's symptoms worsened, and we had no choice but to use TNF- $\alpha$ inhibitors again, preparing for cutbacks from HIRA and planning for the hospital to bear the costs of medication. Because it will be difficult for the hospital to continue to bear the medication costs, we are not sure how we will proceed in the future.

The cases we have described above can be considered side effects of the Korean health insurance system in terms of the assessment process performed by HIRA. These assessments are usually performed by HIRA staff and invited doctors from the relevant fields. Regarding the first case, in Korea, MMN is usually handled by the neurology department; since the assessor asked "Has the patient seen a neurologist?", we can surmise that a neurologist participated in the assessment. We suspect that this is a case in which the patient and hospital faced adverse outcomes due to a power struggle between departments. Moreover, because MMN is a rare disease, it is possible that the assessors lack knowledge or experience in the diagnosis of this disease. In the second case, the extent of sacroiliitis on radiographs can be judged differently by different doctors, and the grade can differ depending on the angle at which the radiographs are taken. It appears that these factors were not considered, and the suitability of treatment was assessed strictly using only the results of the initial radiographs. We also suspect that the criteria might be applied strictly due to the budgetary limitations facing the NHIS. Situations similar to the cases we described occur frequently in Korea, and these cases are damaging the bond of trust that has hitherto existed between doctors and HIRA. Institutional improvements are required to prevent these issues from arising. Assessments should include at least 2 assessors from HIRA, and doctors from different specialties should be recruited to participate in the 
assessment. In addition, when a doctor believes that the HIRA assessment results are unreasonable, there should be a process of mutual discussion and feedback after listening to the doctor's opinions, to produce a more logical assessment. Moreover, the current assessments are performed anonymously, but we believe that ensuring transparency by conducting assessments with a real-name system would help to reduce the likelihood of such side effects. It is also possible to consider solving the fundamental problems of the current assessment system through the introduction of a bundle approach, such as a diagnosis-related group payment system, instead of the fee-for-service system, which assesses each service and action. Finally, rather than assessing each step of the treatment as a separate component, a promising alternative would be to conduct the assessments based on the outcome of the treatment (i.e., treatment outcome, survival rate, and patient satisfaction) and to pay the treatment costs accordingly. Until now, few studies have identified problems in the HIRA review and assessment process and discussed possible improvement plans. In 2005, Jeong [4] reported that the HIRA review criteria contained parts that were somewhat unreasonable or ambiguous, indicating the need to improve the review criteria to be more reasonable based on medically valid input from various departments, rather than the typical unilateral revision of the review criteria by HIRA alone. In 2012, Kim et al. [5] proposed a measure of offering incentives to hospitals and health centers that provide high-quality services, instead of just making cutbacks. In 2019, Korea Medical Association [6] reported that because the medical community has a high level of negative perceptions regarding the current structure and operation of the health insurance system, it is necessary to thoroughly examine the feelings and needs of medical professionals about the fee review system prior to reforming the HIRA review system. Moreover, measures for increasing the participation of physicians in the review system and implementing the review process such that physicians play a central role should be considered.

In conclusion, we have described the problems that can occur in relation to HIRA assessments in Korea through 2 actual clinical cases. We believe that doctors in countries other than Korea may have had experiences similar to those we have described here. Sharing each other's experiences and solutions would help to create a better system. Our study describes only 2 cases and has the shortcoming of raising concerns based only on these 2 cases. The concerns raised through the 2 cases in this study cannot necessarily be generalized to reflect issues in the entire assessment process. Therefore, additional studies are required to investigate and analyze trends in all cases where reimbursements for treatment costs were rejected because HIRA judged the treatments to be inappropriate. Furthermore, it is also deemed necessary to conduct qualitative studies on methods to improve the conflict between HIRA and clinicians through interviews.

\section{Ethics Statement}

This paper is a perspective, so it did not need ethical approval.

\section{CONFLICT OF INTEREST}

The authors have no conflicts of interest associated with the material presented in this paper.

\section{FUNDING}

None.

\section{ACKNOWLEDGEMENTS}

None.

\section{AUTHOR CONTRIBUTIONS}

Conceptualization: DP, MCC. Data curation: DP, MCC. Funding acquisition: None. Writing - original draft: DP, MCC. Writing review \& editing: DP, MCC.

\section{ORCID}

Donghwi Park https://orcid.org/0000-0002-7724-4682

Min Cheol Chang https//orcid.org/0000-0002-7629-7213

\section{REFERENCES}

1. Olney RK, Lewis RA, Putnam TD, Campellone JV Jr; American Association of Electrodiagnostic Medicine. Consensus criteria for the diagnosis of multifocal motor neuropathy. Muscle Nerve 2003;27(1):117-121.

2. Garrett S, Jenkinson T, Kennedy LG, Whitelock H, Gaisford P, Calin A. A new approach to defining disease status in ankylosing spondylitis: the Bath Ankylosing Spondylitis Disease Ac- 
tivity Index. J Rheumatol 1994;21(12):2286-2291.

3. Geijer M, Gadeholt Göthlin G, Göthlin JH. The validity of the New York radiological grading criteria in diagnosing sacroiliitis by computed tomography. Acta Radiol 2009;50(6):664-673.

4. Jeong ST. The proposals for improving and problems of Korean National Health Insurance System Reviewed by orthopaedic surgeon: 1st part: focus on general guide line and the cost of operation. J Korean Orthop Assoc 2005;40(7):1028-1042 (Ko- rean).

5. Kim SM, Jang WM, Ahn HA, Park HJ, Ahn HS. Korean National Health Insurance value incentive program: achievements and future directions. J Prev Med Public Health 2012;45(3):148-155.

6. Korea Medical Association. Review on reform of review system of Health Insurance Review and Assessment Service; 2019 [cited 2020 May 10]. Available from: https://rihp.re.kr/bbs/ board.php?bo_table=research_report\&wr_id=292 (Korean). 